\title{
Numerical simulation of heat exchanger operation
}

\author{
Peter Durcansky ${ }^{1, *}$, and Pavol Orsansky ${ }^{2}$ \\ ${ }^{1}$ University of Žilina, Faculty of Mechanical Engineering, Department of Power Engineering, \\ Univerzitna 1, 01026 Žilina, Slovakia \\ ${ }^{2}$ University of Žilina, Faculty of Mechanical Engineering, Department of Applied mathematics, \\ Univerzitna 1, 01026 Žilina, Slovakia
}

\begin{abstract}
Numerical simulations have opened wide field of possible applications and opportunities to be used not only in science but also in the industry. With new developed numerical methods we can not only describe existing systems, but we can also predict possible behaviour or possible state of inspected system. This article deals with numerical simulation of proposed heat exchanger for hot air engine and with simulation of its possible states and behaviour with certain conditions.
\end{abstract}

\section{Heat source for hot air engine}

Cogeneration unit with hot air engine should be used as an independent source of electrical and heat energy for the household to ensure an efficient energy supply with respect to high reliability. The source of heat is determined by the furnace for burning biomass, in form of a wood pieces, or pellets. Transport energy from the combustion of biomass to a working fluid in hot air engine is providing a heat exchanger connected to that source. In the design of the heat exchanger were taken into account all the conditions imposed on the heat exchanger and the desired properties. Most often the investigation of the heat transfer is the exchanger heat surface $[1,2]$. From this are derived all other parameters, external dimensions, connection dimensions, such as flanges, pipe connecting dimensions, mounting flange dimensions consoles supporting structures. Draft of heat exchanger for hot-air engine had to take into account a wide range of specifications and operating conditions. We have established basic dimensions using the criterion equations. To determine the boundary conditions have been transferred several measurements that confirm and specify the chosen boundary conditions. The basic schema of our proposed micro cogeneration unit is in the Figure 1.

\footnotetext{
${ }^{*}$ Corresponding author: peter.durcansky@fstroj.uniza.sk
} 


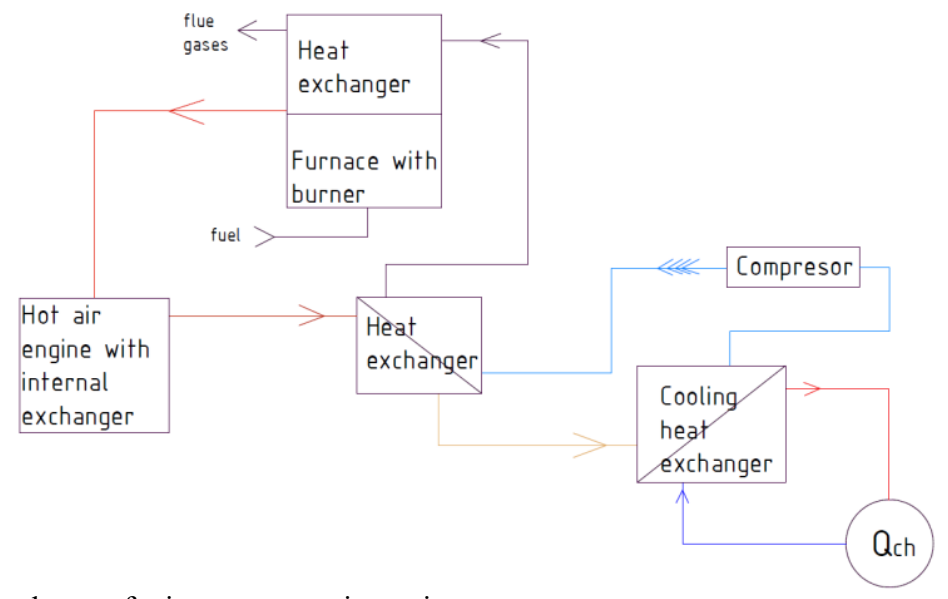

Fig. 1. Principle schema of micro cogeneration unit.

The boiler is fired by biomass. Hot gases are heating the compressed air that flows through the flue gas heat exchanger. In order to increase the efficiency of the system, the flue gas after energy transfer in the heat exchanger, do not leave into atmosphere, but is led through water cooled boiler, which increases the thermal energy transmitted to water. This boiler therefore serves as a heat exchanger and provides an opportunity to gain heat in case of increased demands on thermal energy, for example, in the cold winter months. The compressor is connected into a closed circuit, allowing the use of other working medium such as dry air at a higher pressure. The problem is the need to observe the temperature of the working fluid at the inlet to the compressor at a value prescribed by the manufacturer $[3,4]$. Therefore there are included two heat exchangers. Heat exchanger for hot-air engine is used for recovery of thermal energy from the engine of the medium to the medium that flows from a compressor, heat exchanger serves as a heat receiving regenerator. Next, the cooling heat exchanger, is used for cooling the operating medium before entering the compressor to the required temperature.

\section{Measuring system}

Experimental measurements of the heat source are focused on verification of the boundary conditions in the selected theoretical calculations but also to determine the real characteristics of the proposed device. Also, attention was paid to setting the boiler parameters, especially the amount of air supplied to the boiler. The boiler was placed in the test room and plugged in, as shown in Figure 2. In the combustion chamber, thermocouples are placed, which allow to follow course of temperature in the plane before entering hot flue gas exchanger. At air inlet were placed anemometers, which recorded a rate of air flow to the boiler. Air flow is therefore measured by the indirect method. As heat source was installed into the furnace a gas burner. 


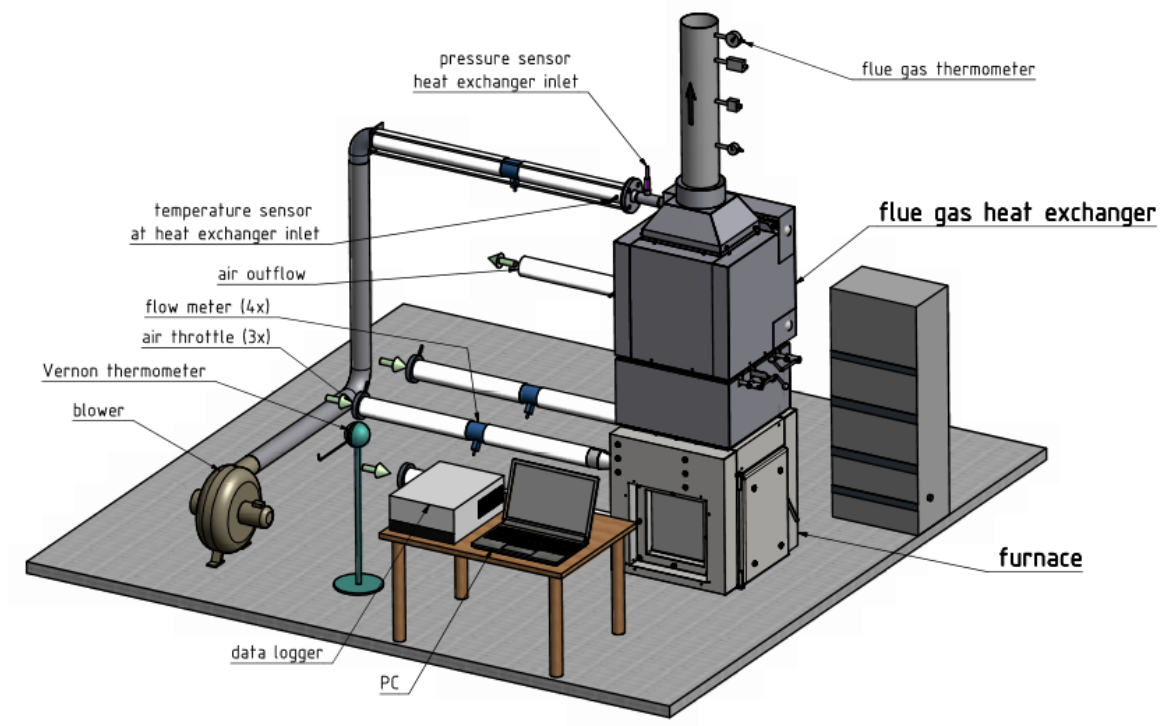

Fig. 2. Measuring system of heat exchanger.

Heat exchanger located in the upper part of the furnace was connected with blower, which feeds the air into the heat exchanger, thus ensuring the flow of air through the exchanger. Observed was the speed of air flow into the heat exchanger, the air temperature at the inlet and outlet of the heat exchanger and also the pressure at the exchanger. All data from the sensors were recorded with logger.

\section{Numerical simulation}

In our simulation we use MatLab - Simulink, which is signal orientated graphical programming environment for dynamic simulations. Blocks are connected via signals.

As we mentioned above, if we have to simulate thermo dynamical systems, it is good to have special tools that enable work in this specific scientific areas. For MatLab Simulink we used the tool Thermolib. To represent all thermodynamic information in an easy to access way, Thermolib uses Simulink busses to represent media flows and thermodynamic states.In models that are based on the Thermolib, the signal flow describing the medium flow between the blocks is described by a so-called flow bus. The flow bus contains the primary information on the flowing media [5,6]. Apart from the total molar flow and the chemical composition, it contains the thermodynamic properties temperature, pressure and vapor fraction.
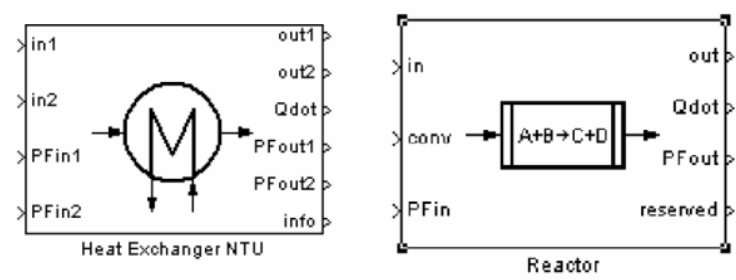

Fig. 3. Two basic parts of proposed Matlab simulation. 
Moreover, it is possible to specify the chemical composition of the medium. Chemical media are the chemical compounds that are available in Thermolib simulations. Some of the default species available are: methane, water, hydrogen gas, oxygen gas, carbon dioxide, among others.

This means that it is sufficient to select individual blocks of the system from the library (e.g.: turbine, expander, cooler and warmers), put it into the model and set the parameters $[7,8]$. Since the simulations runs in real time, the parameters can be changed during the entire simulation. Also the total time of the simulation can be set as finite or infinite, where we have the opportunity to stop the simulation change any parameter and again run the simulation. In each moment of the simulation we are able to know every to obtain each value of parameters of the flow bus, namely: total molar flow, temperature, pressure, enthalpy flow, entropy flow, Gibbs energy rate, heat capacity rate, vapor fraction of all compounds and molar fractions of all compounds [9].

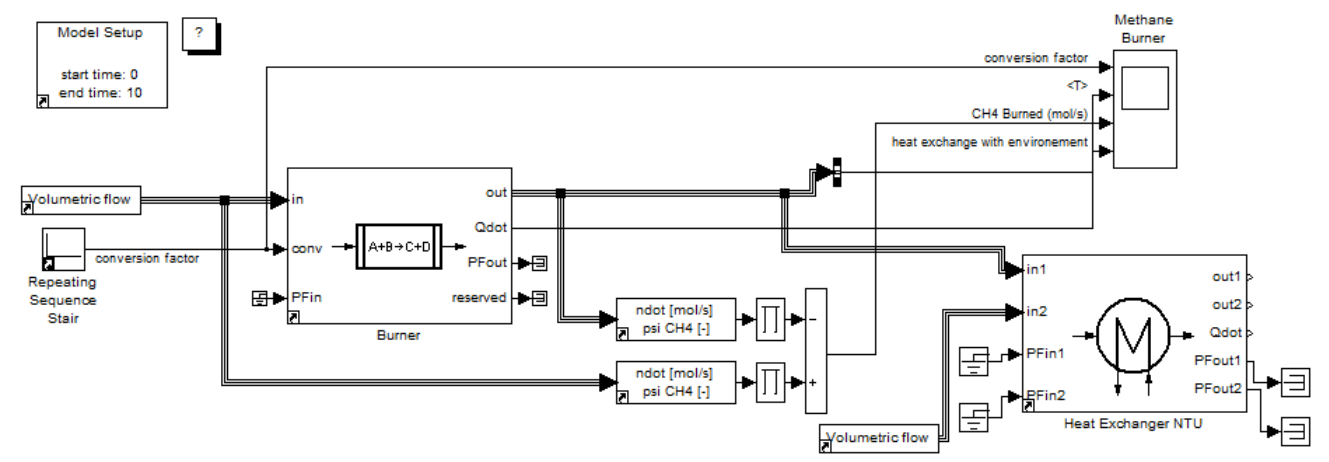

Fig. 4. Simplified numerical model in Matlab.

\section{Conclusion}

Simulation of thermodynamic processes in MatLab environment using block library Thermolib gives many various opportunities to create very useful models. There are countless possibilities of setting individual block components as well as the medium itself. The numerical model can be used for many applications. In our work we focused on exploring various options of involvement and use of this numerical method to describe an existing heat source. First we have made measurements with specified settings to obtain the real behavior of this dynamic system at various conditions. We have observed the system with changed burner power output. After this, the numerical model was adapted to the existing system. Tuned was for all the overall heat transfer rate and also the particular coefficients of heat transfer rate between the two mediums. The power output of the exchanger was then calculated for every setting, as in measurement steps. The results can be seen in the Figure 5. It is clearly to see, that the model is case sensitive and is sensitive at the inputs by small power range. The model produces also an error around $20 \mathrm{~kW}$. But with higher power outputs, the simulation has very good accuracy with small errors.

As next step was added to the model the polynomial regression curve both for measurement and for simulation data, that allowed to predict power output of the furnace. The maximal possible power of the furnace is $35 \mathrm{~kW}$. The numerical model with prediction showed divergence only of $3 \mathrm{~kW}$ at $38 \mathrm{~kW}$ predicted maximal power. 


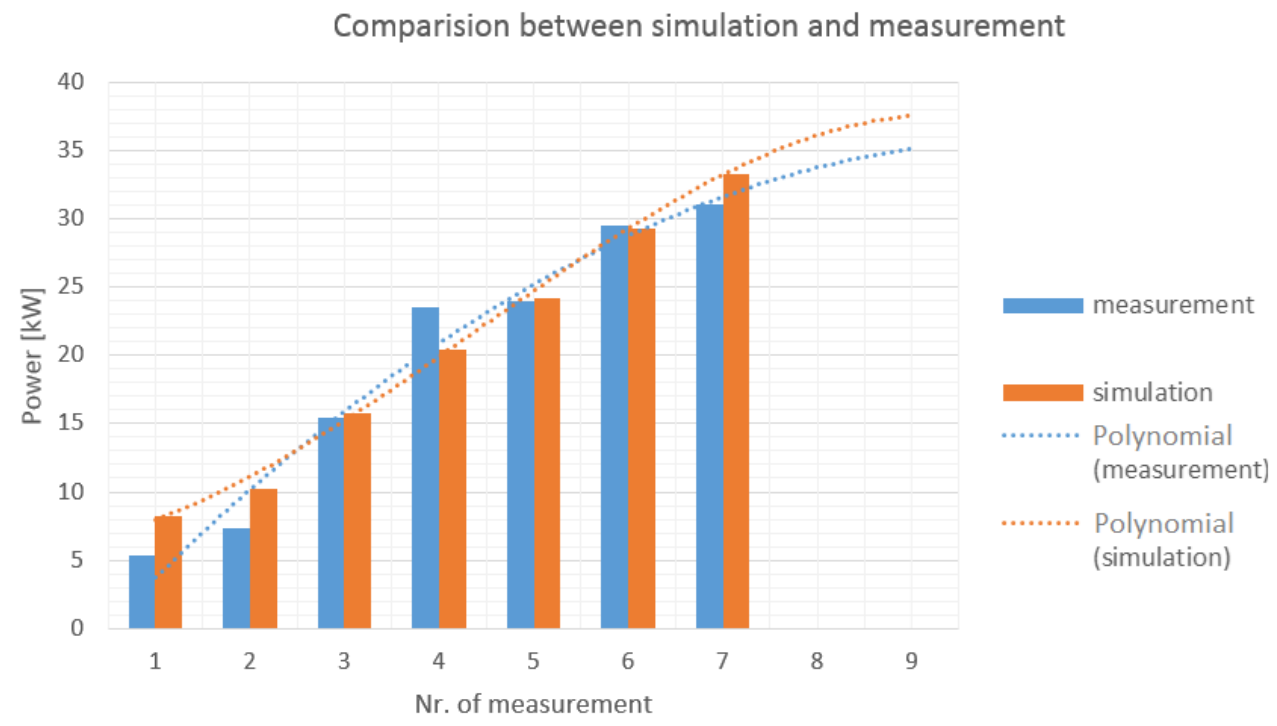

Fig. 5. Results of simplified numerical model.

The research is supported from the project "APVV-15-0778 - The limits of conventional radiation and cooling through the phase change of the working fluid in the thermo-syphon loop” and APVV-15-0790 „Optimization of biomass combustion process with low ash melting temperature“. The project is co-financed by EU funds. Project title: "Research on new methods of heat conversion from RES to electricity using new progressive thermal cycles" ITMS 26220220117

\section{References}

1. R. Nosek, S. Gavlas, R. Lenhard, V. Sedlak, H.M. Arvesen, Communications, 16 (2014)

2. M. Malcho, J. Jandačka, R. Lenhard, S. Gavlas, T. Ochodek, Communications, 18 115-121 (2016)

3. A. Kapjor, K. Kaduchová, R. Lenhard, H. Smatanová, Prenos tepla z orientovaných teplovýmenných plôch pri prirodzenej konvekcii. (2017)

4. T. Brestovič, M. Čarnogurská, R. Pyszko, M. Kubik, XVIII AEaNMiFMaE, 19-26 (2012)

5. B. Skočilasová, J. Skočilas, AIP, 1608, 206-210 (2014)

6. Z. Trávníček, P. Dančová, J.H. Lam, V. Timchenko, J. Reizes,. EPJ Web of Conferences (2012)

7. J. Kn̆ourek, R. Matas, O. Prokeš, D. Tenkrát, EPJ Web of Conferences, 67 (2013)

8. M. Brůna, A. Sládek, Technológ (2011)

9. Michalková M., Michalková L, Applied Mathematical Sciences, 10, 57 (2016) 